\title{
Effect of lifespan and age on reproductive performance of the tardigrade Acutuncus antarcticus: minimal reproductive senescence
}

\author{
Megumu Tsujimoto • Osamu Komori • \\ Satoshi Imura
}

Received: 29 August 2015/Revised: 25 December 2015/Accepted: 7 January 2016/Published online: 8 February 2016

(C) The Author(s) 2016. This article is published with open access at Springerlink.com

\begin{abstract}
Reproductive output is one of the central attributes of life history, and knowledge of agespecific reproduction can enhance the understanding of population performance and dynamics. Tardigrades are microscopic invertebrates that live in marine, freshwater and terrestrial ecosystems. While changes in fertility in relation to age are known to occur in other invertebrate groups, the subject has not been specifically addressed in tardigrades. The current study demonstrates for the first time the effect of lifespan and age on reproductive characteristics of the tardigrade species, Acutuncus antarcticus (Richters 1904), based on the observation of individuals over their entire lifespan under constant environment conditions in the laboratory. Clutch size of $A$. antarcticus fluctuated conspicuously throughout individual lifespans. Weak effects of age were observed on
\end{abstract}

Handling editor: Diego Fontaneto

M. Tsujimoto $(\bowtie) \cdot$ S. Imura

National Institute of Polar Research, 10-3, Midori-cho,

Tachikawa-shi, Tokyo 190-8518, Japan

e-mail: tsujimoto@nipr.ac.jp

O. Komori

The Institute of Statistical Mathematics, 10-3, Midoricho, Tachikawa-shi, Tokyo 190-8518, Japan

S. Imura

SOKENDAI (The Graduate University for Advanced

Studies), 10-3, Midori-cho,

Tachikawa-shi, Tokyo 190-8518, Japan oviposition interval and hatching success, with the former increasing slightly and the latter decreasing slightly with age. Numbers of oviposition events and eggs produced per individual varied greatly and were correlated with lifespan. No significant relationships between clutch size, hatching time or hatching success with lifespan were detected. The majority of the individuals continued oviposition until shortly before death, with no suggestion of a post-reproductive lifespan. Our observations suggest that any decline in fertility with age in this species of tardigrade is minimal. The study provides new insight into the reproductive biology and ageing of invertebrate species.

Keywords Ageing - Fertility · Tardigrada . Antarctica

\section{Introduction}

Reproductive output is one of the central attributes of life history, providing measures of individual and population performance (Lester et al., 2007). It consequently influences patterns of population persistence and contributes to the understanding of species range boundaries (Brown \& Lomolino, 1998; Gaston, 2003). Describing reproductive strategies and assessing fecundity are considered fundamental topics in the study of biology and population dynamics (Hunter 
et al., 1992). Moreover, knowledge of age-specific reproduction can enhance the understanding of population performance and dynamics associated with intrinsic and extrinsic factors, as well as regulatory mechanisms (Del Giudice et al., 2007). Patterns of senescence are highly variable among species and change in fertility in relation to age is also known to vary considerably across different groups of organisms (Jones et al., 2014).

Tardigrades are microscopic invertebrates that live in marine, freshwater and terrestrial ecosystems. In terrestrial habitats, animals are active only when they are surrounded by a film of water (Bertolani et al., 2009). Their ability to enter a cryptobiotic state, in which they can resist physical stresses by effectively switching off metabolism (Keilin, 1959), allows tardigrades to live like aquatic organisms in terrestrial environments and to survive and evolve under sometimes drastic seasonal and diurnal changes in their habitats (Bertolani, 1994; Rebecchi et al., 2007). Marine tardigrades are generally gonochoristic, while the most common mode of reproduction in limnoterrestrial species is parthenogenesis although gonochorism and hermaphroditism occur in some species (Bertolani, 2001). Parthenogenesis in tardigrades generally occurs through apomixis (ameiotic maturation of the oocytes) and is also linked to polyploidy (Bertolani, 1994).

Some data and interpretation relating to reproduction, development and generation time in tardigrade species in natural populations are available (Morgan, 1977; Kathman \& Nelson, 1987; Schuetz, 1987; Schuster \& Greven, 2007, 2013). In addition to the few earlier laboratory studies focused on life history (Baumann, 1964; Dougherty, 1964), traits of several tardigrade species in culture have been described in detail in the last decade (Altiero \& Rebecchi, 2001; Suzuki, 2003; Altiero et al., 2006, 2010, 2015; Hohberg, 2006; Lemloh et al., 2011; Schill, 2013; Tsujimoto et al., 2015). These studies quantified species-specific or population-specific traits including lifespan, age at first oviposition, clutch size, total number of oviposition events, the number of eggs produced per individual and egg development time. However, they did not generally address the effect of lifespan or age on reproductive characteristics.

Without knowledge of changes in fertility or other reproductive parameters over the lifespan, understanding of species-specific or population-specific characteristics of reproduction, thus of the reproductive performance and population dynamics of tardigrade species, remains limited. Therefore, in this study, survival and reproduction of individuals of the tardigrade, Acutuncus antarcticus (Richters, 1904), were studied in detail over their entire lifespan under constant laboratory conditions. The data obtained permit discussion of reproductive senescence of $A$. antarcticus in association with ageing, expanding knowledge of reproductive biology in invertebrate groups.

\section{Materials and methods}

Study species

This study used a culture of the eutardigrade $A$. antarcticus (Richters, 1904) (Hypsibiidae), originally established in the laboratory in 2013 from a phytobenthos sample collected from Hamagiku-Ike Lake in Skarvsnes $\left(69^{\circ} 28^{\prime} \mathrm{S} 39^{\circ} 39^{\prime} \mathrm{E}\right)$ on the Sôya Coast of East Antarctica (Tsujimoto et al., 2015). Acutuncus antarcticus is known to be herbivorous (Dougherty, 1964; Kagoshima et al., 2013). The 68 individuals and their reproductive traits considered in this study are those preliminarily analysed by Tsujimoto et al. (2015). Automictic (thelytokous meiotic) parthenogenesis has been reported recently from a different population of the same species (Altiero et al., 2015).

Culture conditions

Sixty-eight juveniles hatched from eggs randomly selected from the established culture within a 24-h period at $15^{\circ} \mathrm{C}$ were reared in individual wells on culture plates at $15^{\circ} \mathrm{C}$ in the dark. The temperature of $15^{\circ} \mathrm{C}$ was selected as being that which generated the maximum reproductive output of an A. antarcticus sub-sample over a 17-day period (Tsujimoto et al., 2015). Practical limitations on the number of individuals available, and the need to maximize replication meant that we focused our observations at this temperature and were able to obtain a sample size larger than 50 individuals. TPP ${ }^{\circledR}$ tissue culture plates (12 wells, flat bottom) were used with a layer of $300 \mu \mathrm{l}$ of $1.5 \%$ agar gel on the bottom of each well. As a food source, $600 \mu \mathrm{l}$ of $\mathrm{Volvic}^{\circledR}$ water and $1.8 \mu \mathrm{l}$ of a suspension of Chlorella sp. (purchased every three 
weeks from Chlorella Industry Co.) were added to each well. Animals were transferred to new culture dishes and provided with the food source every week, as it is known that overgrowth of bacteria and/or fungi that are problematic in rearing tardigrades can be avoided in this way (Altiero \& Rebecchi, 2001). Additionally, cultures were stored in the dark so as to avoid overgrowth of the algal food source. There was no suggestion of any problems arising from rearing these animals under constant dark conditions.

\section{Lifespan and reproductive traits}

Individual tardigrades were inspected daily and their survival and egg production were monitored. Eggs from each clutch were isolated on the day of oviposition, separated and transferred individually to wells on new culture plates. Subsequent hatching of the isolated eggs was monitored daily until 30 days after oviposition. Data on lifespan, timing and clutch size of each oviposition event, egg development time to hatching (hatching time) and hatching success were recorded. Observations were made using a dissecting microscope (Olympus SZX7) at $\times 56$ magnification.

\section{Statistical analysis}

As not all the data obtained were normally distributed, Kendall's tau statistic was used to determine the correlations of reproductive traits (total number of oviposition events, total number of eggs, age at first oviposition, days from last oviposition to death, clutch size, oviposition interval, hatching time and hatching success) of individuals with their lifespans. Correlations of oviposition intervals, and egg hatching times and success with clutch size were also calculated. Generalized additive mixed models (GAMMs) with an identity link function and a thin plate regression spline smoothing function for estimation (Lin \& Zhang, 1999) were applied to analyse the effect of age on clutch size, oviposition interval, hatching time and hatching success. For GAMM analyses, random intercept models were applied to account for variation between individual tardigrades. R statistical software, version 3.1.1, was used in all the statistical analyses with 'gamm4' package for GAMM.

\section{Results}

Lifespan and lifetime reproduction of Acutuncus antarcticus

Under the laboratory rearing environment at $15^{\circ} \mathrm{C}$, the mean and the median lifespans of $A$. antarcticus individuals were $69.2 \pm 36.4$ and 65 days, respectively (Fig. 1; Table 1). Lifespan, total number of oviposition events and total number of eggs deposited by individuals varied greatly (though all had rightskewed distributions), while age at first oviposition was predominantly 9 or 10 days (Fig. 2; Table 1). Total number of oviposition events, total number of eggs produced per individual and the number of days from last oviposition to death were significantly correlated with lifespan (Table 1). Of the 66 individuals that completed one or more oviposition events, 45 died within 8 days and 50 within 11 days of the last oviposition event.

\section{Oviposition characteristics}

Clutch size variation was apparent both in the overall dataset and between individual tardigrades (Table 2). Of the 508 single clutches recorded, $71.5 \%$ comprised three to six eggs [three eggs $\times 97(19 \%)$; four eggs $\times 89(17 \%)$; five eggs $\times 92(18 \%)$; six eggs $\times 85$ $(17 \%)]$. Although the overall mean oviposition interval of individuals was 9.3 days (Table 2), $79 \%$ of single intervals were between 5 and 8 days amongst the total of 442 intervals recorded. Oviposition interval showed a significant positive correlation with lifespan (Table 2). Both hatching time and success were consistent whether considering eggs produced by individual tardigrades or the overall dataset (Table 2). Oviposition interval and hatching time showed significant negative correlations with clutch size while no significant correlation was identified between hatching success and clutch size (Table 2). Amongst the total of 508 oviposition events recorded, 39 included one or more eggs that did not hatch. Ten of these were produced in the relevant individual's final oviposition event that took place between days 52 and 108, and four individuals had failure eggs in their final two oviposition events. 
Fig. 1 Survival over time for Acutuncus antarcticus under the constant culture conditions applied

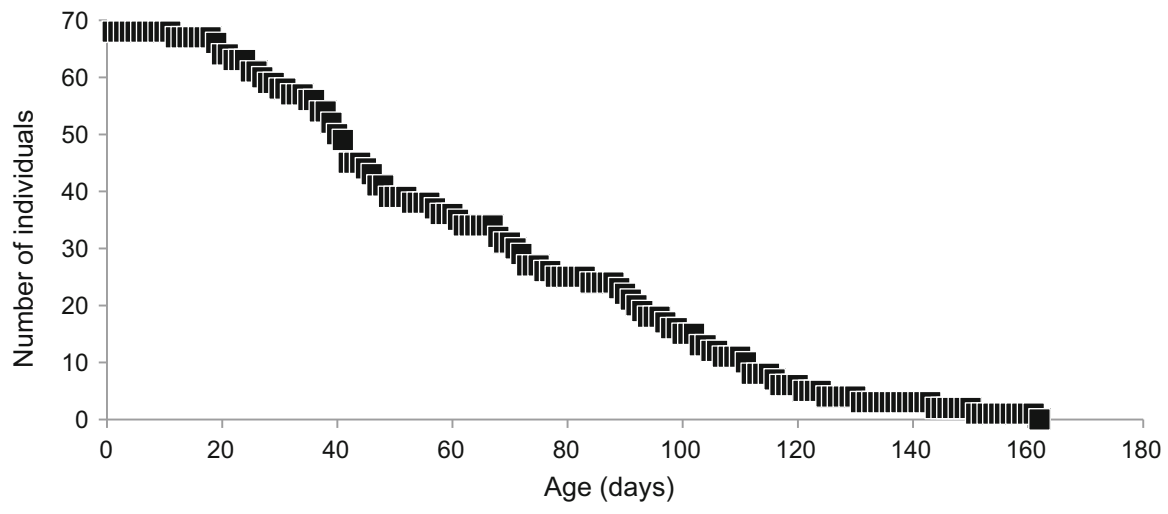

Table 1 Lifespan and lifetime reproductive traits of Acutuncus antarcticus under constant culture conditions at $15^{\circ} \mathrm{C}$

\begin{tabular}{|c|c|c|c|c|c|}
\hline & $\begin{array}{l}\text { Lifespan } \\
\text { (days) }\end{array}$ & $\begin{array}{l}\text { Number of } \\
\text { oviposition events }\end{array}$ & $\begin{array}{l}\text { Number of eggs per } \\
\text { individual }\end{array}$ & $\begin{array}{l}\text { Age at first } \\
\text { oviposition (days) }\end{array}$ & $\begin{array}{l}\text { Days from last } \\
\text { oviposition to death }\end{array}$ \\
\hline Sample size & 68 & 68 & 68 & 66 & 66 \\
\hline Mean $\pm \mathrm{SD}$ & $69.2^{\mathrm{a}} \pm 36.4^{\mathrm{a}}$ & $7.5^{\mathrm{a}} \pm 4.3$ & $34.4^{\mathrm{a}} \pm 22.6^{\mathrm{a}}$ & $9.3^{\mathrm{a}} \pm 1.1^{\mathrm{a}}$ & $9.7 \pm 10.0$ \\
\hline $\begin{array}{l}\text { Minimum- } \\
\text { maximum }\end{array}$ & $12-162^{\mathrm{a}}$ & $0-17$ & $0-97$ & $6-11$ & $1-54$ \\
\hline Median & 65 & 7 & 32 & 10 & 7 \\
\hline $\begin{array}{l}\text { Correlation with } \\
\text { lifespan }\end{array}$ & - & $P<0.001$ & $P<0.001$ & $P=0.14$ & $P=0.003$ \\
\hline $\begin{array}{l}\text { Kendall's } \\
\text { coefficient }\end{array}$ & - & 0.81 & 0.66 & -0.14 & 0.26 \\
\hline
\end{tabular}

Correlations of each reproductive trait of individuals with lifespan were analysed using Kendall's tau statistic

a Data reported in Tsujimoto et al. (2015)

Reproduction with age

Clutch size increased rapidly until 30 days and decreased slightly after 70 days (Fig. 3a). A slight increase in oviposition interval with age was evident (Fig. 3b). Hatching success decreased very slightly with advancing age (Fig. 3c). Of the 16 individuals that survived for more than 100 days, nine produced eggs with a $100 \%$ hatching success throughout their lifetime. Hatching time was virtually constant throughout the 161 days of the study period (Fig. 3d).

\section{Discussion}

Lifespan of $A$. antarcticus varied greatly among the individuals examined, as has been noted in studies of other tardigrade species (Suzuki, 2003; Horikawa et al., 2008; Schill, 2013; Altiero et al., 2015). Considerable variation in lifespan between individuals within isogenic populations under constant laboratory conditions has also been observed in a model animal of ageing studies, the nematode Caenorhabditis elegans (Kirkwood \& Finch, 2002), and also in the monogonont rotifers Asplanchna brightwelli and Brachionus manjavacas (Snell \& King, 1977; Snell et al., 2012).

Clutch size of $A$. antarcticus in relation to age showed a rapid increase from the first oviposition until 30 days. An increase in clutch size early in the reproductive period was also observed in most individuals of the eutardigrade, Milnesium sp., a carnivorous species fed rotifers under experimental laboratory conditions (Suzuki, 2003). Increases in 
(a)

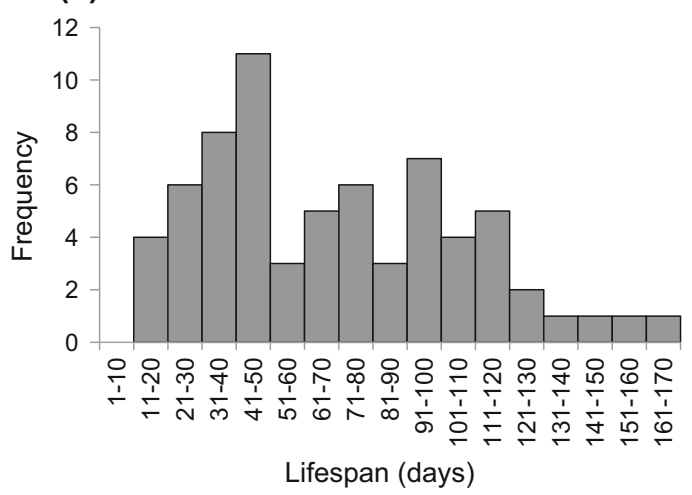

(c)

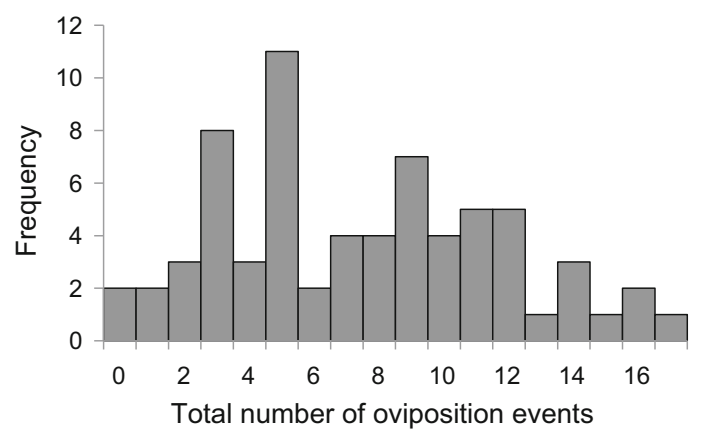

(b)

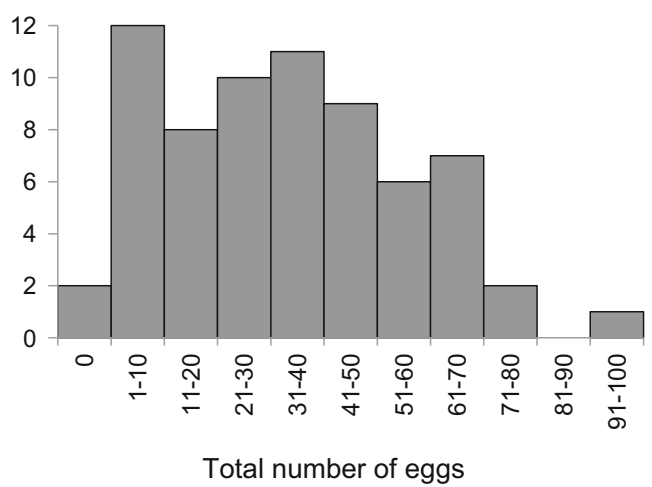

(d)

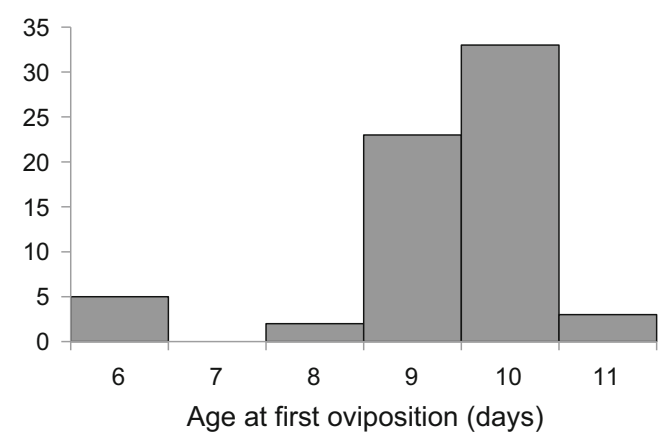

Fig. 2 Frequency distribution of lifespan (days) (a), total number of eggs (b), total number of oviposition events (c) and age at first oviposition (days) $(\mathbf{d})$

clutch size from the first oviposition to the second oviposition of Milnesium sp. occurred during the last stage of their body growth. Large variation in body size of individuals developing eggs was present in a natural population of another eutardigrade species Pseudobiotus kathmanae (Kathman \& Nelson, 1987). A positive correlation between the body length of females and the number of oocytes was reported in three species of eutardigrades in a natural population field study of Macrobiotus hufelandi, Paramacrobiotus richtersi and Diphascon pingue in a moss carpet (Schuster \& Greven, 2013). While no body size data were recorded in our study, a rapid increase in clutch size of A. antarcticus at the beginning of the reproductive period might also suggest that it is a relationship with the growth phase of animals. Weak effects of age were observed on oviposition interval and hatching success. While oviposition interval of $A$. antarcticus showed a small inverse relationship with the fluctuation in clutch size, it increased slightly with age. Hatching success decreased slightly although remaining consistently high throughout the 161 days. While minor negative correlation with clutch size was detected, hatching time remained virtually constant throughout the 161-day period.

In the present study, the numbers of oviposition events and eggs produced per individual varied greatly and were correlated with lifespan. Clutch size fluctuated conspicuously, and oviposition interval increased slightly with age. However, the majority $(71.5 \%)$ of individual clutches contained three to six eggs, and $79 \%$ of the single inter-oviposition intervals were between 5 and 8 days. Most individuals continued reproducing throughout their entire lifespan, and lifespan exerted a stronger effect than specific age on the total number of oviposition events completed and eggs produced per individual. Thus, variation in lifespan was reflected in the considerable variation in the lifetime numbers of oviposition events and eggs. Accordingly, these distributions were right-skewed. Although a significant positive correlation between inter-oviposition interval and lifespan was observed, 
Table 2 Aspects of oviposition of Acutuncus antarcticus under constant culture conditions at $15^{\circ} \mathrm{C}$

\begin{tabular}{|c|c|c|c|c|}
\hline & Clutch size & Oviposition interval (days) & Hatching time (days) & Hatching success $(\%)$ \\
\hline \multicolumn{5}{|c|}{ Lifetime averages for individual tardigrades } \\
\hline Sample size & 66 & $61^{\mathrm{b}}$ & 66 & 66 \\
\hline Mean \pm SD & $4.4 \pm 1.2$ & $9.3 \pm 1.1$ & $8.4 \pm 0.3$ & $97.5 \pm 4.3$ \\
\hline Minimum-maximum & $1.4-6.5$ & $5.0-11.0$ & $7.6-9.0$ & $85.7-100$ \\
\hline Median & 4.6 & 10 & 8.5 & 100 \\
\hline Correlation with lifespan & $P=0.15$ & $P<0.001$ & $P=0.11$ & $P=0.13$ \\
\hline Kendall's coefficient & 0.12 & 0.43 & 0.14 & -0.14 \\
\hline \multicolumn{5}{|l|}{ Overall oviposition events } \\
\hline Sample size & 508 & $442^{\mathrm{c}}$ & 2,286 & 2,342 \\
\hline Mean $\pm \mathrm{SD}$ & $4.6 \pm 1.8$ & $7.7 \pm 3.3$ & $8.5^{\mathrm{a}} \pm 0.7^{\mathrm{a}}$ & $97.6^{\mathrm{a}}$ \\
\hline Minimum-maximum & $1^{\mathrm{a}}-10^{\mathrm{a}}$ & $3^{a}-32$ & $7-12$ & - \\
\hline Median (percentiles 25, 75) & $5(3,6)$ & $7(6,8)$ & $8(8,9)$ & - \\
\hline Correlation with clutch size & - & $P<0.001$ & $P<0.001$ & $P=0.20$ \\
\hline Kendall's coefficient & - & -0.32 & -0.12 & 0.049 \\
\hline
\end{tabular}

Correlations of each reproductive trait of individuals with lifespan and traits of overall oviposition events with clutch size were analysed using Kendall's tau statistic

a Data reported in Tsujimoto et al. (2015)

b Data from individuals undergoing more than three oviposition events were included in these analysis in order to obtain reasonable estimation of the average

${ }^{c}$ Data from clutches from the second oviposition event onwards were analysed. Since the days to the first oviposition include time of growth and do not represent a true oviposition interval, we calculated the intervals beginning from the days between the first and second oviposition events

no significant relationships between clutch size, hatching time or hatching success and lifespan were detected. While the hatching time of A. antarcticus was very stable across individuals in the current study, observations of a different population of the same species using a different rearing method indicate the possibility of phenotypic plasticity over generations in some of the reproductive parameters examined here including hatching time and success (Altiero et al., 2015). High variability in hatching time has also been reported within clones of the eutardigrade Macrobiotus richtersi (Altiero et al., 2006, 2010).

In the population of parthenogenetic tardigrade $A$. antarcticus studied here, while the duration of the period from last oviposition to death increased slightly with lifespan, the majority of the individuals continued oviposition until shortly before death, with no suggestion of a post-reproductive lifespan which is typical in mammals and also in some invertebrate groups (Cohen, 2004; Jones et al., 2014). Similarly, individuals of another tardigrade, Milnesium sp., also reproduced continuously throughout their life (Suzuki, 2003). The slight decrease in clutch size of $A$. antarcticus observed here after 70 days might suggest a small decline in fecundity after the mean lifespan at 69.2 days, but overall hatching success remained very high throughout the 161-day study period, decreasing very slightly. A major decrease of hatching success was observed between 50 and 110 days, when ten individuals produced one or two clutches including one or more eggs that did not hatch shortly before their death. However, more than half of the individuals that lived for more than 100 days produced egg batches with $100 \%$ hatching success throughout their lifespan and, as a result, hatching success was not significantly correlated with lifespan. Moreover, there was no effect of age or lifespan on hatching time. Together, these observations suggest that any decline in fertility with age in this species of tardigrade is minimal.

Senescence is usually indicated by age-related declines in survival and reproduction in association with progressive physiological deterioration (Kirkwood \& Austad, 2000). Senescence is well documented in a variety of animals including wild populations of birds and mammals (Nussey et al., 2013). Among invertebrate species, the ageing process 
(a)

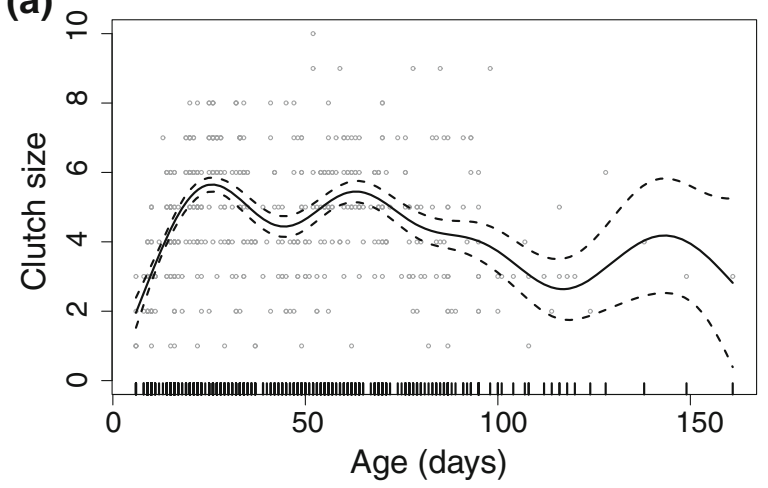

(c)

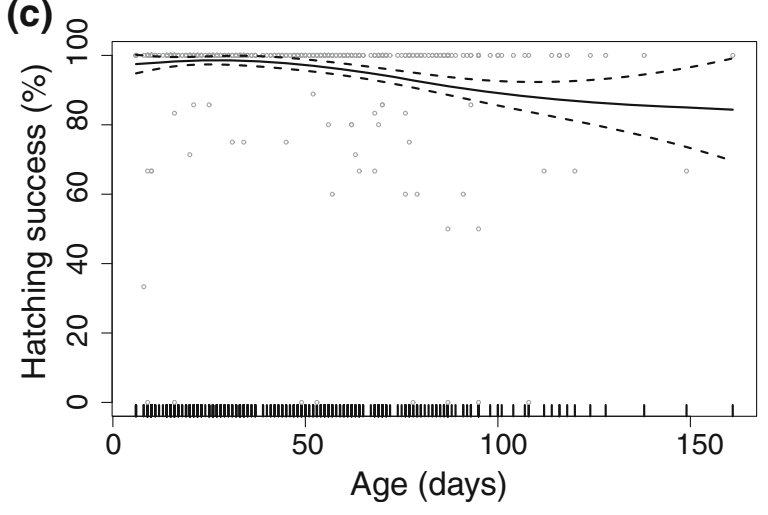

(b)

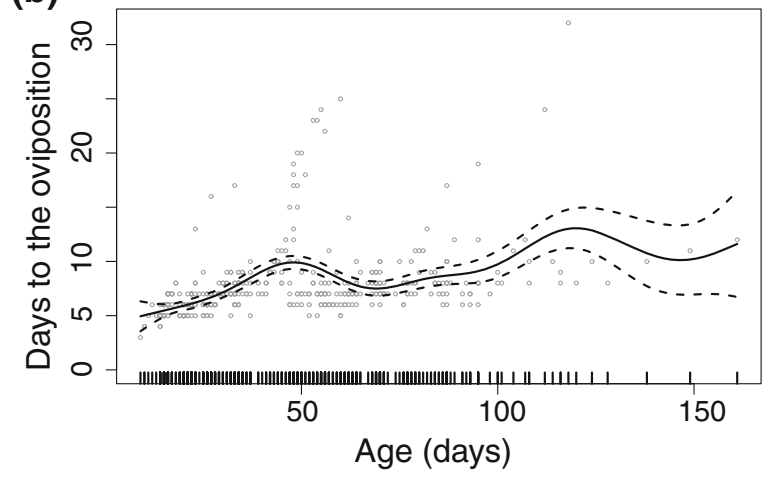

(d)

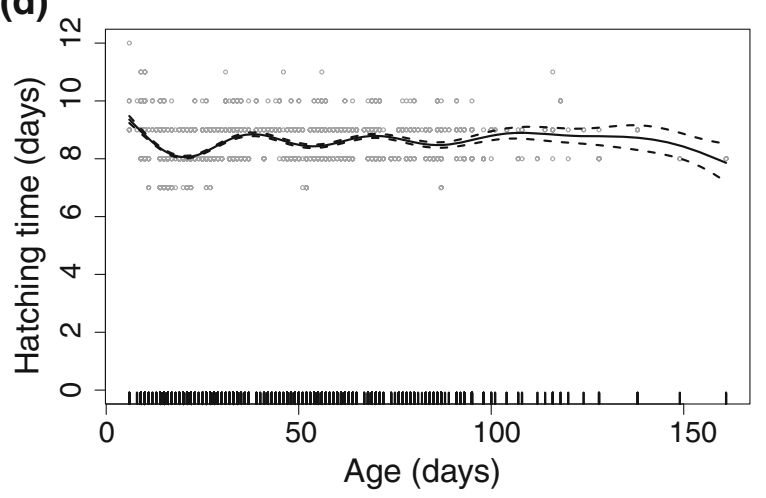

Fig. 3 Generalized additive mixed models (GAMMs) with thin plate regression spline for estimation of clutch size (a), oviposition interval (days) (b), hatching success (\%) (c) and hatching time (days) (d). Dashed lines represent $95 \%$ confidence limits

in model species such as the nematode $C$. elegans and the fruit fly Drosophila melanogaster is the most studied (Dillin et al., 2002; Herndon et al., 2002; Giannakou et al., 2004). Reproductive senescence has been reported in both species, where rapid declines in fecundity begin at young to middle age due to the limitation of the fixed store of sperm in hermaphrodite C. elegans and apoptosis of ageing egg chambers in $D$. melanogaster (Hughes et al., 2007; Zhao et al., 2008). Fecundity peaks at very early ages followed by rapid declines have also been observed in the parthenogenetic bdelloid rotifers Adineta ricciae and Macrotrachela quadricornifera (Ricci et al., 1987; Ricci \& Covino, 2005). In rotifers, the maximum potential fecundity of a female is fixed by the number of oocytes in her germarium (Gilbert, 1993). Decline in oocyte number is considered a major determinant of reproductive senescence in female mammals (Cohen, 2004). In the parthenogenetic tardigrade $A$. antarcticus, no information is available on oocyte numbers, but it would appear that neither the number of oocytes nor the ageing of the reproductive organs restricts the continued successful reproduction of this species throughout its lifespan. The pattern of reproductive performance as a function of age in A. antarcticus is similar to those of the parthenogenetic water flea Daphnia longispina and the sexually reproducing human louse Pediculus humanus (see Jones et al., 2014).

Acutuncus antarcticus is known to be widespread in both terrestrial and freshwater habitats in Antarctica (McInnes, 1995; Gibson et al., 2007; Tsujimoto et al., 2014; Velasco-Castrillón et al., 2014). The natural environment in Antarctica is considered the most extreme and variable on Earth in terms of low temperature, limited water availability and short growing season (Smith, 1988; Peck et al., 2006). Asexual reproduction is considered an ancestral feature present in many of the major groups of invertebrates that are components of ecosystems in more extreme environments including Antarctica (Convey, 2010). Life cycle extension is widely used 
by many taxa to survive in low-energy and 'adversity selected' environments such as those of Antarctica in order to overcome insufficient time to complete a full reproductive cycle within one season (Convey, 1996; Block et al., 2009). While prolonged survival has been hypothesised to be sacrificed for higher reproduction at early ages in some unfavourable environments (Kirkwood \& Rose, 1991), prolonged maintenance of reproductive ability also gives an advantage in extended life cycles in the natural environment of Antarctica. In addition to the possession of parthenogenesis and anhydrobiosis, which are known to be important contributors to successful establishment in unstable environments for some micro-invertebrates including tardigrades (Bertolani, 2001) and bdelloid rotifers (Ricci, 1987), the minimal reproductive senescence of $A$. antarcticus revealed in our study might also be an important factor contributing to the successful establishment and widespread distribution of this species within the Antarctic region.

The in-depth analyses described here of reproductive traits collected from daily observations of $A$. antarcticus under constant laboratory conditions demonstrated, for the first time, the effect of lifespan and age on reproductive performance in a member of the phylum Tardigrada. Knowledge of the relationship between fertility and age, and of changes in reproductive characteristics over the lifespan, will improve our understanding of reproductive performance and population dynamics of tardigrades in the natural environment. While reproductive senescence has been observed in other groups of animals, no clear evidence was found in this tardigrade species, providing new insight into the reproductive biology and ageing of these invertebrates.

Acknowledgments We thank Akinori Takahashi for useful discussions and suggestions in statistical analysis. Peter Convey, Sandra J. McInnes, Atsushi C. Suzuki and two anonymous reviewers offered constructive comments and advice. This study was supported by Grant-in-Aid for Scientific Research No. 23247012 to S.I. and No. 26650168 to M.T. from the Japan Society for the Promotion of Science. This paper also contributes to the Scientific Committee on Antarctic Research AntEco research programme.

Open Access This article is distributed under the terms of the Creative Commons Attribution 4.0 International License (http:// creativecommons.org/licenses/by/4.0/), which permits unrestricted use, distribution, and reproduction in any medium, provided you give appropriate credit to the original author(s) and the source, provide a link to the Creative Commons license, and indicate if changes were made.

\section{References}

Altiero, T. \& L. Rebecchi, 2001. Rearing tardigrades: results and problems. Zoologischer Anzeiger 240: 217-221.

Altiero, T., L. Rebecchi \& R. Bertolani, 2006. Phenotypic variations in the life history of two clones of Macrobiotus richtersi (Eutardigrada, Macrobiotidae). Hydrobiologia 558: 33-40.

Altiero, T., R. Bertolani \& L. Rebecchi, 2010. Hatching phenology and resting eggs in tardigrades. Journal of Zoology 280: 290-296.

Altiero, T., I. Giovannini, R. Guidetti \& L. Rebecchi, 2015. Life history traits and reproductive mode of the tardigrade Acutuncus antarcticus under laboratory conditions: strategies to colonize the Antarctic environment. Hydrobiologia 761: 277-291.

Baumann, H., 1964. Über den Lebenslauf und die Lebensweise von Milnesium tardigradum Doyère (Tardigrada). Veröffentlichungen aus dem Überseemuseum Bremen 3: 161-171.

Bertolani, R., 1994. Tardigrada. In Adiyodi, K. G. \& R. G. Adiyodi (eds), Reproductive Biology of Invertebrates, Vol. 6B. - Asexual Propagation and Reproductive Strategies. Oxford \& IBH Publishing Co, New Delhi: 25-37.

Bertolani, R., 2001. Evolution of the reproductive mechanisms in tardigrades-a review. Zoologischer Anzeiger 240: 247-252.

Bertolani, R., T. Altiero \& D. R. Nelson, 2009. Tardigrada (Water Bears). In Likens, G. E. (ed), Encyclopedia of Inland Waters, Vol. 2. Elsevier, Oxford: 443-455.

Block, W., R. I. L. Smith \& A. D. Kennedy, 2009. Strategies of survival and resource exploitation in the Antarctic fellfield ecosystem. Biological Reviews 84: 449-484.

Brown, J. H. \& M. V. Lomolino, 1998. Biogeography, 2nd ed, Sinauer Associates, Sunderland.

Cohen, A. A., 2004. Female post-reproductive lifespan: a general mammalian trait. Biological Reviews 79: 733-750.

Convey, P., 1996. The influence of environmental characteristics on life history attributes of Antarctic terrestrial biota. Biological Reviews 71: 191-225.

Convey, P., 2010. Life-history adaptations to polar and alpine environments. In Denlinger, D. L. \& R. E. Lee Jr. (eds), Low Temperature Biology of Insects. Cambridge University Press, Cambridge: 297-321.

Del Giudice, G. D., M. S. Lenarz \& M. C. Powell, 2007. Agespecific fertility and fecundity in northern free-ranging white-tailed deer: evidence for reproductive senescence? Journal of Mammalogy 88: 427-435.

Dillin, A., D. K. Crawford \& C. Kenyon, 2002. Timing requirements for insulin/IGF-1 signaling in C. elegans. Science 298: 830-834.

Dougherty, E., 1964. Cultivation and nutrition of micrometazoa. II. An Antarctic strain of the tardigrade Hypsibius arcticus (Murray, 1907) Marcus, 1928. Transactions of the American Microscopical Society 83: 7-11.

Gaston, K. J., 2003. The Structure and Dynamics of Geographic Ranges. Oxford University Press, Oxford.

Giannakou, M. E., M. Goss, M. A. Jünger, E. Hafen, S. J. Leevers \& L. Partridge, 2004. Long-lived Drosophila 
with over-expressed dFOXO in adult fat body. Science 305: 361.

Gibson, J. A. E., L. Cromer, J. T. Agius, S. J. McInnes \& N. J. Marley, 2007. Tardigrade eggs and exuviae in Antarctic lake sediments: insights into Holocene dynamics and origins of the fauna. Journal of Limnology 66(s1): 65-71.

Gilbert, J. J., 1993. Rotifera. In Adiyodi, K. G. \& R. G. Adiyodi (eds), Reproductive Biology of Invertebrates, Vol. 6A Asexual Propagation and Reproductive Strategies. Oxford \& IBH Publishing Co, New Delhi: 231-263.

Herndon, L. A., P. J. Schmeissner, J. M. Dudaronek, P. A. Brown, K. M. Listner, Y. Sakano, M. C. Paupard, D. H. Hall \& M. Driscoll, 2002. Stochastic and genetic factors influence tissue-specific decline in ageing $C$. elegans. Nature 419: 808-814.

Hohberg, K., 2006. Tardigrade species composition in young soils and some aspects on life history of Macrobiotus richtersi J. Murray, 1911. Pedobiologia 50: 267-274.

Horikawa, D. D., T. Kunieda, W. Abe, M. Watanabe, Y. Nakahara, F. Yukuhiro, T. Sakashita, N. Hamada, S. Wada, T. Funayama, C. Katagiri, Y. Kobayashi, S. Higashi \& T. Okuda, 2008. Establishment of a rearing system of the extremotolerant tardigrade Ramazzottius varieornatus: a new model animal for astrobiology. Astrobiology 8: 549-556.

Hughes, S. E., K. Evason, C. Xiong \& K. Kornfeld, 2007. Genetic and pharmacological factors that influence reproductive aging in nematodes. PLoS Genetics 3: e25.

Hunter, J. R., B. J. Macewicz, N. C. H. Lo \& C. A. Kimbrell, 1992. Fecundity, spawning, and maturity of female Dover sole, Microstomus pacificus, with an evaluation of assumptions and precision. Fishery Bulletin. United States Fish and Wildlife Service 90: 101-128.

Jones, O. R., A. Scheuerlein, R. Salguero-Gómez, C. G. Camarda, R. Schaible, B. B. Casper, J. P. Dahlgren, J. Ehrlén, M. B. García, E. S. Menges, P. F. Quintana-Ascencio, H. Caswell, A. Baudisch \& J. W. Vaupel, 2014. Diversity of ageing across the tree of life. Nature 505: 169-173.

Kagoshima, H., S. Imura \& A. C. Suzuki, 2013. Molecular and morphological analysis of an Antarctic tardigrade, Acutuncus antarcticus. Journal of Limnology 72(s1): 15-23.

Kathman, R. D. \& D. R. Nelson, 1987. Population trends in the aquatic tardigrade Pseudobiotus augusti (Murray). In Bertolani, R. (ed), Biology of Tardigrades: Selected Symposia and Monographs. Modena, Mucchi Editore: $155-168$.

Keilin, D., 1959. The problem of anabiosis or latent life: history and current concept. Proceedings of the Royal Society of London Series B: Biological Sciences 150: 149-191.

Kirkwood, T. B. L. \& M. R. Rose, 1991. Evolution of senescence: late survival sacrificed for reproduction. Philosophical Transactions: Biological Sciences 332: 15-24.

Kirkwood, T. B. L. \& S. N. Austad, 2000. Why do we age? Nature 408: 233-238.

Kirkwood, T. B. L. \& C. E. Finch, 2002. The old worm turns more slowly. Nature 419: 794-795.

Lemloh, M. L., F. Brummer \& R. O. Schill, 2011. Life history traits of the bisexual tardigrades Paramacrobiotus tonollii and Macrobiotus sapiens. Journal of Zoological Systematics and Evolutionary Research 49(s1): 58-61.
Lester, S. E., S. D. Gaines \& B. P. Kinlan, 2007. Reproduction on the edge: large-scale patterns of individual performance in a marine invertebrate. Ecology 88: 2229-2239.

Lin, X. \& D. Zhang, 1999. Inference in generalized additive mixed models by using smoothing splines. Journal of the Royal Statistical Society Series B 61: 381-400.

McInnes, S. J., 1995. Tardigrades from Signy Island, South Orkney Islands, with particular reference to freshwater species. Journal of Natural History 29: 1419-1445.

Morgan, C. I., 1977. Population dynamics of two species of Tardigrada, Macrobiotus hufelandii (Schultze) and Echiniscus (Echiniscus) testudo (Doyère), in roof moss from Swansea. Journal of Animal Ecology 46: 263 -279.

Nussey, D. H., H. Froy, J. F. Lemaître, J. M. Gaillard \& S. N. Austad, 2013. Senescence in natural populations of animals: Widespread evidence and its implications for biogerontology. Ageing Research Reviews 12: 214-225.

Peck, L. S., P. Convey \& D. K. A. Barnes, 2006. Environmental constraints on life histories in Antarctic ecosystems: tempos, timings and predictability. Biological Reviews 81: 75-109.

Rebecchi, L., T. Altiero \& R. Guidetti, 2007. Anhydrobiosis: the extreme limit of desiccation tolerance. Invertebrate Survival Journal 4: 65-81.

Ricci, C., 1987. Ecology of bdelloids: how to be successful. Hydrobiologia 147: 117-127.

Ricci, C., L. Vaghi \& M. L. Manzini, 1987. Desiccation of rotifers (Macrotrachela quadricornifera): survival and reproduction. Ecology 68: 1488-1494.

Ricci, C. \& C. Covino, 2005. Anhydrobiosis of Adineta ricciae: costs and benefits. In Herzig, A., R. D. Gulati, C. D. Jersabek \& L. May (eds), Rotifera X: Rotifer Research: Trends, New Tools and Recent Advances, Vol. 546. Springer, Dordrecht: 307-314.

Schill, R. O., 2013. Life-history traits in the tardigrade species Paramacrobiotus kenianus and Paramacrobiotus palaui. Journal of Limnology 72(s1): 160-165.

Schuster, R. \& H. Greven, 2007. A long-term study of population dynamics of tardigrades in the moss Rhytidiadelphus squarrosus (Hedw.) Warnst. Journal of Limnology 66(s1): 141-151.

Schuster, R. \& H. Greven, 2013. Reproductive traits of Macrobiotus hufelandi during a long-term field study with notes on Paramacrobiotus richtersi and Diphascon pingue (Eutardigrada). Journal of Limnology 72(s1): 166-174.

Schuetz, G., 1987. A one-year study on the population dynamics of Milnesium tardigradum Doyère in the lichen Xanthoria parietina (L.) Th. Fr. In Bertolani, R. (ed), Biology of Tardigrades: selected Symposia and Monographs. Mucchi Editore, Modena: 217-228.

Smith, R. I. L., 1988. Recording bryophyte microclimate in remote and severe environments. In Glime, J. M. (ed), Methods in Bryology. Hattori Botanical Laboratory, Miyazaki: 275-284.

Snell, T. W. \& C. E. King, 1977. Lifespan and fecundity patterns in rotifers: the cost of reproduction. Evolution 31(4): 882-890.

Snell, T. W., A. M. Fields \& R. K. Johnston, 2012. Antioxidants can extend lifespan of Brachionus manjavacas (Rotifera), but only in a few combinations. Biogerontology 13: 261-275. 
Suzuki, A. C., 2003. Life history of Milnesium tardigradum Doyère (Tardigrada) under a rearing environment. Zoological Science 20: 49-57.

Tsujimoto, M., S. J. McInnes, P. Convey \& S. Imura, 2014. Preliminary description of tardigrade species diversity and distribution pattern around coastal Syowa Station and inland Sør Rondane Mountains, Dronning Maud Land, East Antarctica. Polar Biology 37: 1361-1367.

Tsujimoto, M., A. C. Suzuki \& S. Imura, 2015. Life history of the Antarctic tardigrade, Acutuncus antarcticus, under a constant laboratory environment. Polar Biology 38: 1575-1581.

Velasco-Castrillón, A., J. A. E. Gibson \& M. I. Stevens, 2014. A review of current Antarctic limno-terrestrial microfauna. Polar Biology 37: 1517-1531.

Zhao, R., Y. Xuan, X. Li \& R. Xi, 2008. Age-related changes of germline stem cell activity, niche signaling activity and egg production in Drosophila. Aging Cell 7: 344-354. 